\title{
Commentary: Adjuvant intensity-modulated radiation therapy for malignant pleural mesothelioma: Suspension of intention
}

\author{
Shawn S. Groth, MD, MS, Bryan M. Burt, MD, and R. Taylor Ripley, MD
}

\footnotetext{
From the Mesothelioma Treatment Center, Division of Thoracic Surgery, Michael E. DeBakey Department of Surgery, Baylor College of Medicine, Houston, Tex.

Disclosures: Authors have nothing to disclose with regard to commercial support.

Received for publication March 9, 2019; accepted for publication March 11, 2019; available ahead of print April $25,2019$.

Address for reprints: Shawn S. Groth, MD, MS, Division of Thoracic Surgery, Michael E. DeBakey Department of Surgery, One Baylor Plaza, BCM 390, Houston, TX 77030 (E-mail: Shawn.Groth@bcm.edu).

J Thorac Cardiovasc Surg 2019;158:932-3

$0022-5223 / \$ 36.00$

Copyright (C) 2019 Published by Elsevier Inc. on behalf of The American Association for Thoracic Surgery

https://doi.org/10.1016/j.jtcvs.2019.03.023
}

The most common site of recurrence after cytoreductive surgery for malignant pleural mesothelioma (MPM) is within the ipsilateral, surgically treated hemithorax, highlighting the locally aggressive nature of this tumor and the need for multimodal treatment strategies. In an effort to decrease the risk of local recurrence, multiple studies have assessed the use of adjuvant radiation therapy. Compared with historical controls, the balance of the literature has suggested that adjuvant radiotherapy is beneficial in terms of improving progression-free and overall survival after extrapleural pneumonectomy (EPP) ${ }^{1}$ and pleurectomy/decortication (P/D). ${ }^{2}$ To minimize the risk of radiation exposure to healthy surrounding tissue (and the attendant risk of radiation pneuomonitis), computed tomography simulation-guided planning using intensitymodulated radiation therapy (IMRT) is a preferred radiation modality for MPM. Multimodal therapy can be difficult for patients to complete. In several studies of trimodality therapy for MPM, only $40 \%$ to $50 \%$ of patients were able to complete all intended treatments. ${ }^{3,4}$ If the intention of multimodal therapy is to optimize progression-free and overall survival, then failure to complete a planned regimen may be a detriment to achieving these objectives. Therefore, it is important to understand barriers to delivering all intended treatments.

In this issue of the Journal, Nelson and colleagues ${ }^{5}$ conducted a single institution review of 160 patients with MPM who were treated with a trimodality strategy (neoadjuvant platinum/pemetrexed chemotherapy, P/D or EPP, and adjuvant IMRT) over a 13-year period with the primary aim of identifying risk factors for failing to complete adjuvant IMRT. $^{5}$ They found that patient comorbid conditions (defined by an American Society of Anesthesiologists score of $3+$ and smoking history) were independent predictors of inability to complete IMRT. These results are not surprising. Patients with severe systemic disease have less reserve

\section{References}

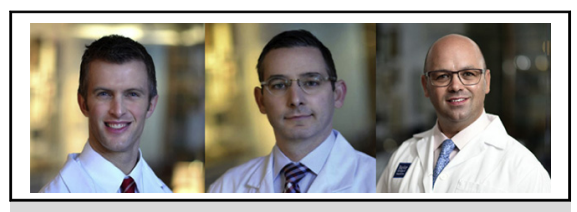

Shawn S. Groth, MD, MS, Bryan M. Burt, MD, and R. Taylor Ripley, MD

\section{Central Message}

Careful patient selection is critical to maximizing the probability that patients with MPM complete all intended treatments of multimodal therapy.

See Article page 924

to tolerate the rigors of an aggressive multimodal treatment plan that includes EPP or P/D. Although it is often assumed that $\mathrm{P} / \mathrm{D}$ is a less demanding operation in terms of a patient's recovery, the type of resection did not predict receipt of IMRT. Unfortunately, American Society of Anesthesiologists score or number of pack-years of tobacco use are usually nonmodifiable risks by the time patients present with MPM. Therefore, this study highlights that careful patient selection is critical to maximizing the probability that all planned treatments are completed. Although unknown, perhaps optimizing medical management of systemic diseases, use of physical and respiratory rehabilitation, and improved nutrition could improve rates of IMRT completion among borderline surgical candidates.

The importance of perioperative complications as a barrier to completing a treatment plan is also highlighted in this study. Patients who had cardiopulmonary complications were half as likely to complete IMRT as patients who did not. Proactive postoperative care is essential to mitigate the risk of complications, minimize their impact when they arise, and potentially maximize the probability of patients completing their intended treatment plan.

As operationalization of healthcare quality becomes increasingly important, understanding barriers to delivering quality care becomes critical for our patients.

1. Krug LM, Pass HI, Rusch VW, Kindler HL, Sugarbaker DJ, Rosenzweig KE, et al. Multicenter phase II trial of neoadjuvant pemetrexed plus cisplatin followed by extrapleural pneumonectomy and radiation for malignant pleural mesothelioma. J Clin Oncol. 2009;27:3007-13. 
2. Rimner A, Zauderer MG, Gomez DR, Adusumilli PS, Parhar PK, Wu AJ, et al. Phase II Study of Hemithoracic Intensity-Modulated Pleural Radiation Therapy (IMPRINT) as part of lung-sparing multimodality therapy in patients with malignant pleural mesothelioma. J Clin Oncol. 2016;34:2761-8.

3. Federico R, Adolfo F, Giuseppe M, Lorenzo S, Martino DT, Anna C, et al. Phase II trial of neoadjuvant pemetrexed plus cisplatin followed by surgery and radiation in the treatment of pleural mesothelioma. BMC Cancer. 2013;13:22.
4. de Perrot M, Feld R, Cho BC, Bezjak A, Anraku M, Burkes R, et al. Trimodality therapy with induction chemotherapy followed by extrapleural pneumonectomy and adjuvant high-dose hemithoracic radiation for malignant pleural mesothelioma. J Clin Oncol. 2009;27:1413-8.

5. Nelson DB, Rice DC, Mitchell KG, Tsao AS, Gomez DR, Sepesi B, et al. Return to intended oncologic treatment after surgery for malignant pleural mesothelioma. J Thorac Cardiovasc Surg. 2019;158:924-9. 